\title{
Minithoracotomy oesophagectomy for oesophageal carcinoma with aberrant right subclavian artery: a rare case of dysphagia
}

\author{
Duminda Subasinghe ${ }^{1 *}$, Hemantha Sudasinghe ${ }^{1}$, Chathuranga Tisara Keppetiyagama', Sumana D Handagala ${ }^{2}$,
} Anuja Abayadeera ${ }^{1}$ and Merrenna IM De Zoysa ${ }^{1}$

\begin{abstract}
Background: Aberrant R/subclavian artery is a rare congenital anomaly involving aortic arch. Oesophageal carcinoma with associated aberrant $\mathrm{R} /$ subclavian artery is very rare and only few cases has been reported in literature. If unrecognized and injured during oesophageal surgery, it can lead to disastrous complications. When associated with oesophageal carcinoma, it can cause diagnostic confusion as the symptoms are similar.

Case presentation: A 60 year old previously healthy female presented with intermittent dysphagia, odynophagia and loss of weight of 3 months duration. She was found to have a oeophageal carcinoma with incidentally co-existing aberrant R/subclavian artery.

Conclusion: Although rare this entity should be considered as a differential diagnosis in a patient with dysphagia. In addition, pre-operative identification is important to prevent intra operative vascular complications. The diagnosis and treatment of this rare condition is discussed in this article.
\end{abstract}

Keywords: Aberrant subclavian artery, Oesophageal carcinoma, Dysphagia lusoria

\section{Background}

An aberrant right subclavian artery (ARSCA) is an unusual congenital anomaly although a well described entity. ARSCA is often an incidental finding on imaging studies and it affects about $0.5 \%$ to $1.8 \%$ in the general population [1]. In over $80 \%$ of cases, the location is posterior to the oesophagus [2]. When associated with oesophageal carcinoma, it can cause diagnostic confusion as the symptoms are similar.

In normal individuals the right subclavian artery (RSCA) arises from the brachiocephalic artery. Embryologically, the proximal part of the RSCA develops from the right fourth aortic arch and the distally from the seventh intersegmental artery [3]. In ARSCA, abnormal development results from degeneration of the entire right fourth arch. The right seventh intersegment artery persists in its attachment to the distal descending aorta [4].

\footnotetext{
* Correspondence: dumindas1982@yahoo.com

${ }^{1}$ University Surgical Unit, The National Hospital of Sri Lanka, Colombo, Sri Lanka

Full list of author information is available at the end of the article
}

The ARSCA consequently originates from the aorta distal to the left subclavian artery, and passes behind the oesophagus and trachea toward the right [4]. The right recurrent nerve is also abnormal and passes directly to the larynx from the vagus rather than "recurring" from the chest [4].

If unrecognized and injured during open or minimally invasive oesophageal surgery, it can lead to disastrous complications. Therefore as a surgeon, awareness about this anomaly is important in order to prevent catastrophic hemorrhage from laceration of the ARSCA. Transhiatal oesophagectomy for cancer is proposed in order to decrease postoperative morbidity [5]. Mediastinal haemorrhage during transhiatal oesophagectomy occurs in $1 \%$ to $9 \%$ of procedures, usually from injury to the aorta or azygous vein [6,7].

\section{Case presentation}

A 60 year old previously healthy female presented with intermittent dysphagia, odynophagia and loss of weight of 3 months duration. Her symptoms were non progressive. 
She was otherwise well. Physical examination was unremarkable except her BMI was $16 \mathrm{~kg} / \mathrm{m}^{2}$. Her upper gastrointestinal endoscopy revealed a superficial mucosal irregularity from $25-35 \mathrm{~cm}$ with friability and contact bleeding. There was no evidence of external compression of the oesophagus on endoscopy. The biopsy of oesophageal lesion revealed a well differentiated squarmous cell carcinoma. Her preoperative contrast enhanced CT of thorax and abdomen showed a normal oesophagus without any luminal lesions or wall thickening. However, it showed an abnormal right subclavian artery (Figure 1) running behind the thoracic oesophagus above the carina. There was no evidence of locoregional spread, mediastinal lympadenopathy or evidence of distant metastases. Therefore she was planned for a transthoracic oesophagectomy.

The thoracic cavity was approached by a mini thoracotomy [8] as it provides adequate access to the oesophagus, aberrant vessel and associated with less post-operative respiratory complications when compared to conventional posterolateral thoracotomy. The oesophagus was mobilized from lower end to up wards. During thoracic oesophageal mobilization, there was an abnormal retrooesophageal $\mathrm{R} /$ subclavian artery arising from aortic arch above the carina (Figure 2). An upper abdominal incision followed by a cervical incision were also made to mobilize the stomach and create a cervical oesophagogastric anastomosis. Mediastinal lymphadenectomy was done. Cervical lymphadenectomy was not performed. The patient was managed in the surgical intensive care unit for 6 days. On post-operative day 2, she was extubated and gradually mobilized and started on chest physiotherapy. During this period she was well and recovery was uneventful. She was transferred to the surgical ward on post operative day seven and died suddenly most probably due to cardiac arrest or massive pulmonary embolism. Histopathological analysis of resected specimen of oesophagus (Figure 3) showed a well differentiated squarmous cell carcinoma (pT1NOR0).

\section{Discussion}

Dysphagia is a common problem encountered in surgical practice and result in low quality of life in patients. Oesophageal dysphagia could be caused by oesophageal carcinoma, benign stricture and webs, achalasia, diffuse oesophageal spasm and scleroderma [9]. Although, ARSCA (lusoria artery) is a rare cause of dysphagia it's the most common abnormality of the aortic arch. Dysphagia lusoria was first described by Bayford in 1787 [10]. Intraoperative damage to this artery during oesophageal surgery may lead to disastrous complications. Only few cases of oesophageal cancer with associated ARSCA are reported in literature [11-14].

The surgical approach to oesophageal carcinoma is determined by the location of the tumour as well as the surgical expertise available. Transhiatal oesophagectomy

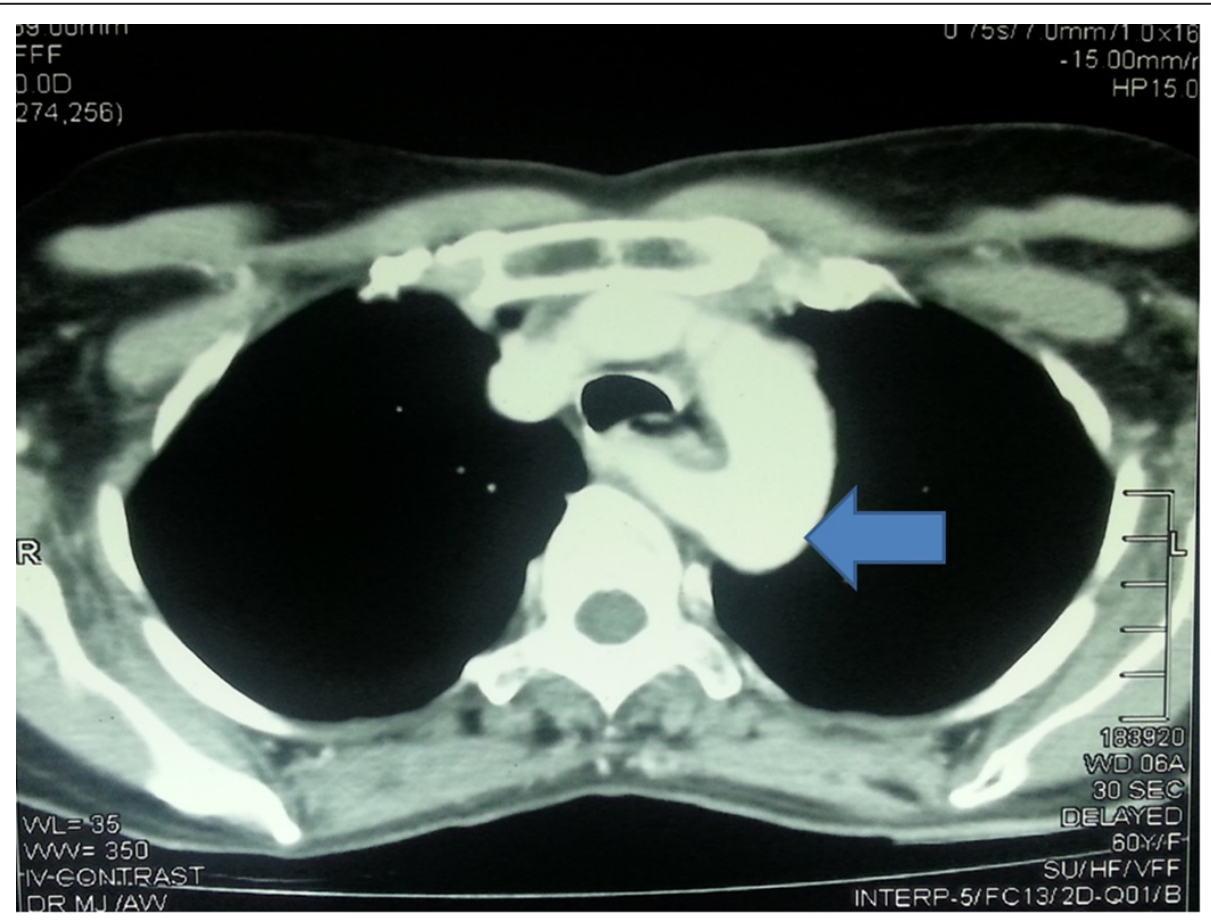

Figure 1 Contrast enhaced CT thorax showing the course of aberrant R/subcalvian artery behind the oesophagus (blue arrow shows the aberrant vessel). 


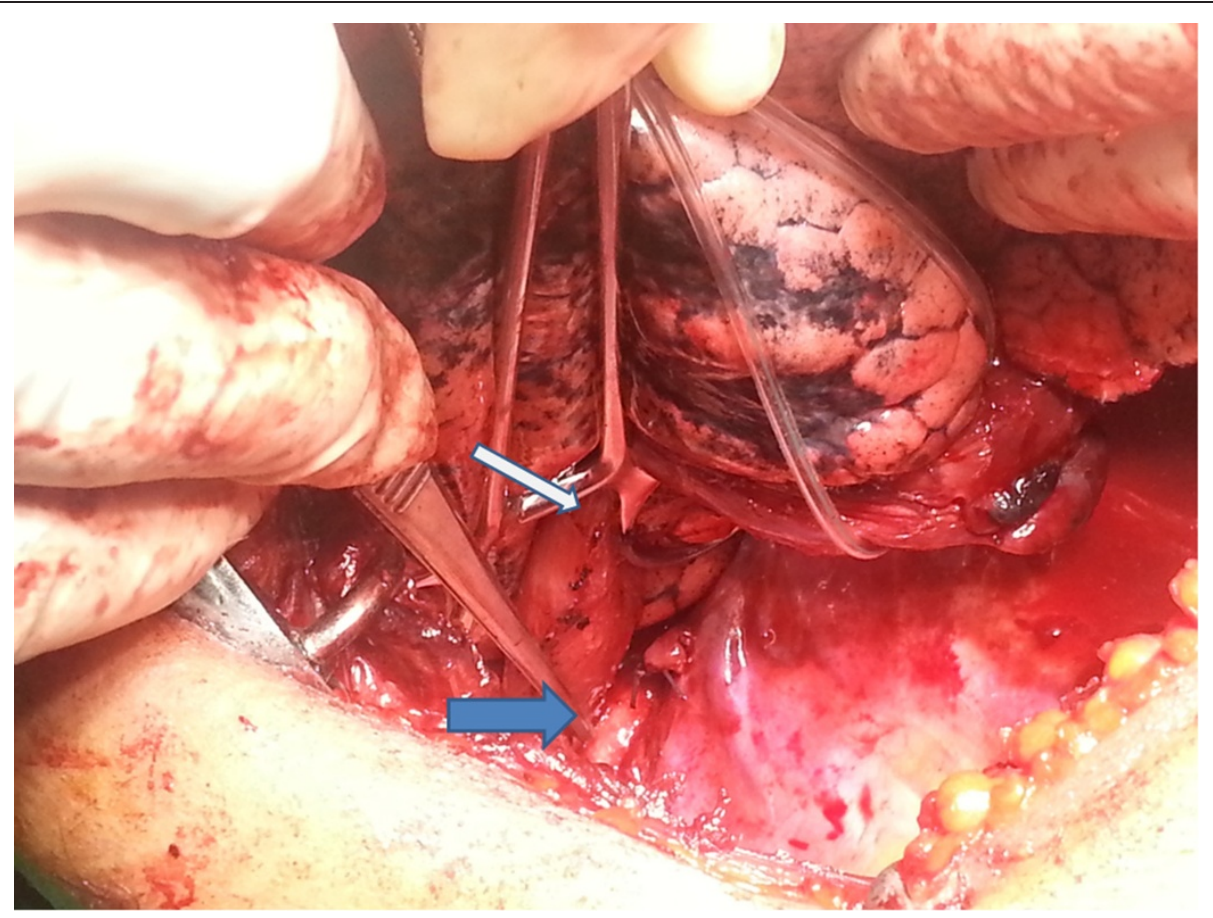

Figure 2 Aberrant R/subclavian artery (blue arrow) identified following mobilization of thoracic oesophagus (white arrow).

(THE) for cancer is proposed in order to reduce the postoperative morbidity. The major inconvenience during the THE is blind mediastinal dissection. In addition, the presence of ARSCA can complicate the preoperative or postoperative course especially due to fistula formation and bleeding $[11,15]$. Therefore we planned for a transthoracic procedure in our patient. Mediastinal hemorrhage during THE occurs in $1 \%$ to $9 \%$ of procedures, usually from injury to the aorta or azygous vein [7]. An ARSCA is also at significant risk for injury during mobilization of the

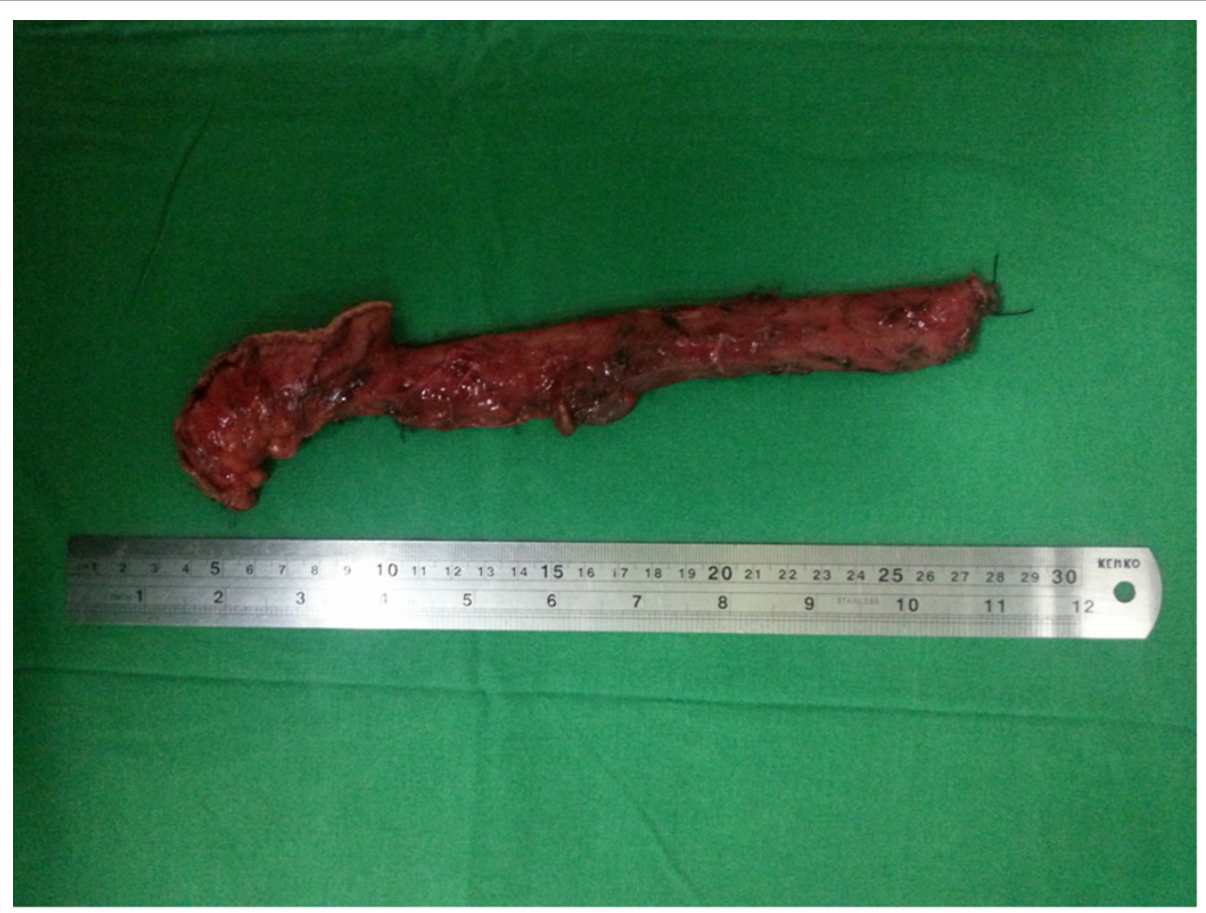

Figure 3 Resected specimen of oesophagus. 
oesophagus through the cervical and transhiatal routes. Pre-operative diagnosis will require a very high index of suspicion and radiologic investigations. This was evident in our case because oesophagus was patent on upper gastrointestinal endoscopy except an area of mucosal irregularity which could not explain the degree of dysphasia in our patient. This also confirmed on contrast CT thorax and abdomen where the oesophageal was normal thickness without any evidence of growth. But it showed an abnormal retro-oesophageal artery.

\section{Conclusion}

Therefore we would conclude that although rare this entity should be considered as a differential diagnosis in a patient with dysphagia. In addition, pre-operative identification and careful dissection during oesophageal mobilization will help in preventing disastrous vascular complications in patients with an ARSCA who undergo oesophagectomy.

\section{Consent}

Written informed consent was obtained from the patient and relatives for publication of this case report and any accompanying images. A copy of the written consent is available for review by the Editor of this journal.

\section{Competing interests}

The authors declare that they have no competing interests.

\section{Authors' contributions}

All six authors were involved in planning, data collection, analysis of case and writing the manuscript. DS collected data and wrote the paper. IDZ critically revised the article. IDZ,SDH, DS,CTK, HS,AA made substantial contributions to patient management and supervised the manuscript. All authors read and approved the manuscript.

\section{Acknowledgement}

The authors acknowledge all the ward staff who took care of the patient.

\section{Author details}

'University Surgical Unit, The National Hospital of Sri Lanka, Colombo, Sri Lanka. ${ }^{2}$ Department of Thoracic Surgery, National Hospital for Respiratory Diseases, Welisara, Sri Lanka.

Received: 29 September 2013 Accepted: 18 September 2014

Published: 21 September 2014

\section{Reference}

1. Miller RG, Robie DK, Davis SL, Cooley DA, Klish WJ, Skolkin MD, Kearney DL, Jaksic T: Survival after aberrant right subclavian artery-oesophageal fistula: case report and literature review. J Vasc Surg 1996, 24:271-275.

2. Stone WM, Brewster DC, Moncure AC, Franklin DP, Cambria RP, Abbott WM: Aberrant right subclavian artery: varied presentations and management options. J Vasc Surg 1990, 11:812-817.

3. Lichter I: The treatment of dysphagia lusoria in adults. Br J Surg 1963, 50:793-796.

4. Wind GG, Valentine RJ (Eds): Anatomic exposures in vascular surgery. Baltimore: Williams and Wilkins; 1991:445-452.

5. Pop D, Venissac N, Mouroux J: Video-assisted mediastinoscopy improved radical resection for cancer in transhiatal esophagectomy. $J$ Thorac Cardiovasc Surg 2007, 133:267-268.

6. Katariya K, Harvey JC, Pina E, Beattie EJ: Complications of transhiatal esophagectomy. J Surg Oncol 1994, 57:157-163.

7. Gandhi SK, Naunheim KS: Complications of transhiatal esophagectomy. Chest Surg Clin North Am 1997, 7:601-610.
8. Narumiya K, Nakamura T, Ide H, Takasaki K: Comparison of extended esophagectomy through mini-thoracotomy/laparotomy with conventional thoracotomy/laparotomy for esophageal cancer. Jpn J Thorac Cardiovasc Surg 2005, 53(8):413-419.

9. Barloon TJ, Bergus GR, Lu CC: Diagnostic imaging in the evaluation of dysphagia. Am Fam Physician 1996, 53:535-546.

10. Bayford D: An account of a singular case of obstructed deglutition, Mem M Society London 2271, 1787.

11. Pop D, Venissac N, Nadeemy AS, Schneck A-S, Aze O, Mouroux J: Lesson to be learned: beware of lusoria artery during transhiataloesophagectomy. Ann Thorac Surg 2012, 94:1010-1011.

12. Pantvaidya GH, Mistry RC, Ghanekar VR, Upasani W, Pramesh CS: Injury of an Aberrant Subclavian Artery:A Rare Complication of Video Assisted Thoracoscopic oesophagectomy. Ann Thorac Cardiovasc Surg 2005, 11:35-37.

13. Thomas Temes R, Tullis MJ, Patty L, Jorge A: Wernly transhiatal oesophagectomy in a patient with aberrant right subclavian artery. Ann Thorac Surg 1999, 68:2341-2342.

14. Lin Y, Li M, Liu XJ: berrant right subclavian artery in video-assisted thoracoscopic esophagectomy. Thorac Dis 2013, 5(4):E137-E139.

15. Millar A, Rostom A, Rasuli P, Saloojee N: Upper gastrointestinal bleeding secondary to an aberrant right subclavian artery-esophageal fistula: a case report and review of the literature. Can J Gastroenterol 2007, 20:389-392.

doi:10.1186/1471-230X-14-163

Cite this article as: Subasinghe et al:: Minithoracotomy oesophagectomy for oesophageal carcinoma with aberrant right subclavian artery: a rare case of dysphagia. BMC Gastroenterology 2014 14:163.

\section{Submit your next manuscript to BioMed Central and take full advantage of:}

- Convenient online submission

- Thorough peer review

- No space constraints or color figure charges

- Immediate publication on acceptance

- Inclusion in PubMed, CAS, Scopus and Google Scholar

- Research which is freely available for redistribution 